\title{
THE POLITICS OF MOTHER TONGUE EDUCATION: THE CASE OF UGANDA
}

\author{
Medadi Ssentanda, Makerere University, Uganda \& Stellenbosch University \\ Kate Huddlestone, Stellenbosch University \\ Frenette Southwood, Stellenbosch University
}

This paper aims to explain the trend of mother tongue (MT) education in Uganda by examining particularly the government's practices towards MT education. Because of disappointing levels of literacy attained by learners, MT education was (re)introduced in Uganda in 2006/2007 with the hope of improving literacy skills particularly among rural children. Based on data gathered from rural schools (both government and private), this paper questions what exactly it is that government seeks to reclaim, restore and/or rejuvenate in Uganda's education system via MT education

\section{Luganda translation of abstract}

Olupapula luno luluubirira okwanika omugendo gw'okusomesereza mu nnimi enzaaliranwa mu Uganda. Kino kijja kukolebwa n'okwebuuza ebibuuzo ku ebyo gavumenti by'ekola ku kusomesereza mи nnimi enzaaliranwa. Okusomesereza mu nnimi enzaaliranwa kwazuukusibwa nate mu Uganda mu 2006/2007 wakati mu mbeera y'okuyiga okusoma n'okuwandiika eyennyamiza. Okusomera mu nnimi enzaaliranwa kwazuukusibwa n'ekigendererwa ekikulu eky'okwongera ku mutindo gw'okuyiga okusoma n'okuwandiika

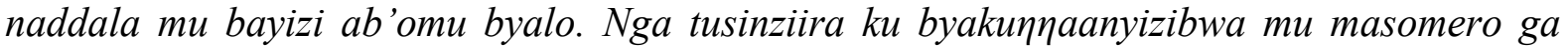
gavumenti n'ag 'obwannannyini ag'oти byalo, olupapula luno lulimu okwebuuza ebibuuzo ku ekyo gavumenti ky'eruubirira okukomyawo, okuzzaawo oba n'okwongeramu amaanyi mu muyungiro gw'ebyenjigiriza mu Uganda ng'eyitira mu kusomesereza mu nnimi enzaaliranwa.

\section{INTRODUCTION}

Many countries, particularly those in the global south, are focusing on employing languages in education in a manner that would bring about meaningful learning. Linguistic and educational innovations are, however, often met with challenges pertaining to language policy and planning, especially considering that there is a mostly top-down arrangement as regards language in education in most countries. Such top-down forms of language policy and planning might involve 'hidden agendas' (see below), as Shohamy (2006) observes.

Kaplan and Baldauf (1997: 3) define language planning as an 'attempt by someone to modify the linguistic behaviour of some community for some reason'. This means that, when a language is assigned a particular status, those assign the status have an aim in doing so. For instance, language planning during colonial times involved identifying languages to develop for specific purposes (Ricento, 2006). In Uganda's case, English was promoted during the colonial era with the aim of producing administrators for the colonial government (Ssekamwa, 2000). Considering Kaplan and Baldauf's (1997: 3) definition of language planning (given above), any language-in-education policy has an agenda, be it implicit or explicit. As stated in this regard by UNESCO (1997: 36) in their 1997 report on Intergovernmental conference on 
language policies in Africa, 'language policy is ultimately a political decision that can only be taken by government'.

'Politics' refers to 'the activities involved in getting and using power in public life, and being able to influence decisions that affect a country or a society' (Turnbull, 2010). This paper will reveal that people with political power can indeed influence and control the use of language(s) in schools. This influence can take many forms - for example, approving the implementation of a specific language-in-education policy or the production (or lack thereof) of teaching and learning materials in a particular language.

Ever since the introduction of formal education in Uganda, attempts have been made to employ mother tongues (MTs) ${ }^{1}$ as languages of learning and teaching (LoLTs). These endeavours at one time included the use of dominant languages, area languages or languages of wider communication as LoLTs (cf. Government of Uganda, 1992; Kajubi, 1989), followed by stages during which English was used exclusively as LoLT (Lasebikan, Ismagilova \& Hurel, 1964). Given the multilingual nature of Uganda (over 45 languages are spoken in Uganda), and its desire to seek national and regional integration, Swahili has also been proposed as a national language and LoLT, but with very limited success (Ssekamwa, 2000, 2008). In Uganda, language-in-education policy and language planning have not always occurred in a synchronised manner and, as such, there have been periods during which there was no clear plan to direct teaching and learning, particularly in primary schools. For example, the most recent language-in-education policy was proclaimed in 1992 (Government of Uganda, 1992), but the commitment towards policy implementation only became operational in 2006/2007.

The use of MTs in Uganda's education system has greatly diminished in the post-independence era and English has taken centre stage, but without an improvement in the low literacy levels across the country (e.g. see reports of Mango Tree Laךo Literacy Project, 2010; Piper \& Miksick, 2011; Uganda National Examinations Board, 2010; Uwezo, 2011, 2012). This paper questions what exactly it is that Uganda's MT education policy of 2006/2007 seeks to reclaim, restore and/or rejuvenate. In considering this matter, the paper seeks to uncover possible hidden political agendas in the implementation of the current language-in-education policy. In order to provide background information against which the current policy can be considered, a historical overview of MT education in Uganda is given in the next section.

\section{Mother tongue education in Uganda: a historic overview}

According to Ferguson (2013) and Ball (2011), the employment of MT education in African contexts has been informed by politics, economics and ideology rather than by educational considerations (cf. Ssentanda, 2013; Stroud, 2001, 2002; Tollefson, 1991). This section considers the motive behind the MT education policies in Uganda thus far. Special consideration is given to the current policy that apparently started as one calling for the use of dominant languages in schools but now allows the use of all local languages that meet the National Curriculum Development Centre criteria for a LoLT.

In the 1940s to 1960 s, there were plans to develop and recruit MTs for use in the Ugandan education system (Lasebikan et al., 1964: 16). Attempts were made to use so-called languages of wider communication in various districts in Uganda. For instance, in 1946, the Education Directors passed the following policy on the use of MTs in education: 
1. The main African languages spoken in each area should be the sole medium of instruction throughout the primary school (Standard I - VI), provided it were sufficiently developed and widespread to justify the production of the necessary textbooks.

2. The African languages in small areas only should be used as a medium of instruction for primary I in the district, after which children should be taught in one of the more widespread African languages.

With this policy in place, six languages were recognised as LoLTs in the following year (1947) (Lasebikan et al., 1964: 16):

Luganda, Lunyoro [sic], Lugbara, Teso, Lwo, and Swahili. In addition to these Runyankore was to be allowed during the first two years (Standard I and II) in [what was then the] Ankole [kingdom], as well as Kumam in Teso districts, and Karamojong in Karamoja district. English was to be taught as a subject in the fifth and sixth years.

This policy was in place until 1963, when a new policy was proposed by the Uganda Education Commission, namely, that the LoLT be limited to Akaramojong, Ateso, Luganda, Lugbara, Lwo, Runyankore-Rukiga and Runyoro-Rutoro (thus grouping Runyankore-Rukiga and Runyoro-Rutoro ${ }^{2}$ as language clusters, and eliminating Teso and Swahili as possible LoLTs).

Lasebikan et al. (1964) report that the circumstances in place at that time would make the Education Commission's policy of limiting the LoLT to the above seven languages impractical, for two reasons: (i) in most urban schools, classes consisted of learners from different language backgrounds, and (ii) if a language has no reading materials, literacy acquisition in that language becomes difficult. These challenges led to English being introduced as LoLT in areas where a dominant local language could not easily be identified. For the areas in which MTs were used as LoLT, English was introduced as a subject in $\mathrm{P}^{3}$ and as a LoLT in P4.

In the 1960s, strategies were put in place for a national literacy campaign. Lasebikan et al. (1964) point out that, despite the challenges faced in the implementation thereof, the government division in charge of the campaign (the Division of Community Development) laid down a clear strategy as regards language teaching. ${ }^{4}$ During this time, efforts for the development of MT education were in high gear and involved communities and parents. By contrast, the lack of community involvement and sensitisation is a challenge to the present implementation of MT education in Uganda (Tembe \& Norton, 2008).

By 1964, 20 languages were identified to receive attention for development as LoLTs (Lasebikan et al., 1964). Seventeen of these had literacy primers and follow-up readers for adult literacy, and three were in the process of preparing such primers and readers. By comparison, in 2006/2007, there were only nine languages that were said to have developed orthographies and reference materials and that were therefore fit for use as LoLTs in primary schools (Kateeba, 2009). The question arises as to what happened to the orthographies developed for the other 11 languages. The fact that these languages do not have sufficient materials to be used as LoLT points towards fluctuating levels of effort to develop Ugandan languages.

A 1985 UNESCO report on African community languages and their use in literacy and education (UNESCO Regional Office for Education in Africa, 1985) indicated that, at the time, 
only eight languages were used as LoLTs for the first three or four school years in Uganda, namely Ateso, Kiswahili, Luganda, Lugbara, Luo, Runyankore, Rukiga and Rutoro. These languages were used 'in first level education, as a medium of instruction in years 1-5 and as a compulsory subject in years 6-7' (UNESCO Regional Office for Education in Africa, 1985: 73).

Between 1960s and 2006/2007, the use of MTs in Uganda's primary education was not formalised, and it was mostly a practice in rural schools. On reintroducing MT education in Uganda in 1992 in principle, but mostly because of the language-in-education policy guidelines issued in 2006/2007, the issue of languages of wider communication resurfaced. Today, these are regarded as Luganda, Lwo, Runyakitara/Runyoro-Rutoro and Runyankore-Rukiga, Ateso/Akaramojong and Lugbara (Government of Uganda, 1992), the classification being based on the intelligibility of these languages to speakers of certain other languages. It was hoped that the employment of languages of wider communication would simplify the implementation of MT as LoLT - that is, speakers of the mutually intelligible languages in a certain group were expected to engage in MT teaching and learning under a certain language label. For instance, speakers of the minority languages Soga, Samia and Luuri (among others) were expected to engage in Luganda as LoLT as their languages were categorised as mutually intelligible with Luganda. Such an arrangement has been criticised by scholars as violating linguistic justice and linguistic human rights because it denies speakers of minority languages an opportunity to learn in their MTs (e.g. see Heugh, Benson, Bogale, \& Yohannes, 2007; Kirkpatrick, 2013; Stroud, 2001).

In 2006/2007, room was again made for the use of MTs and/or languages of wider communication as LoLT for the first three years of schooling in rural primary schools (Kateeba, 2009; Ministry of Education \& Sports, 2004, 2008; National Curriculum Development Centre, 2006a, 2006b, 2011). (Thereafter, in the fourth year, a transition to English takes place, and from the fifth year onwards English is used as the only LoLT.) By contrast, urban schools, because of their assumed 'complex multilingualism', use English as LoLT throughout primary schooling but have to teach MTs as subjects. There are, however, no guidelines on how urban schools choose a language to be taught as MT when in fact they cannot choose one to use as LoLT. The current language-in-education policy was introduced simultaneously with a themebased curriculum which is purportedly more child-friendly than the old subject-based curriculum (Kateeba, 2009; National Curriculum Development Centre, 2006c).

Against this background, this paper attempts to show how, over time, Uganda's language-ineducation policies have intrinsically promoted English at the expense of MTs. Considering Bourdieu's (1991) work on language and symbolic power, the question arises as to whether language-in-education policies in Uganda have the inherent aim of exclusion, that is, of keeping the 'capital' within a small minority.

\section{METHOD}

The data reported here are part of an ethnographic study that focused on how Ugandan teachers understand and manage the process of transitioning from MT education to English as LoLT. Data were collected in 10 schools between the months of September and November 2012. Eight schools were rural (from Rakai and Oyama districts, in the south and north of the country, respectively) and two were urban (from Kampala district, the capital of Uganda). Data collection involved the use of questionnaires, classroom observations, follow-up interviews, 
note-taking and document analysis. Data were analysed thematically (cf. Saldana, 2009) and quantitatively, the latter with SPSS (although no quantitative data are reported in this paper). The policy documents were analysed by means of critical discourse analysis in order to point out the contradictions in definitions and stipulations of the policy. Such contradictions might generate different interpretations of the policy, ultimately instigating a gap between policy and practice. All interviews and classroom observations were conducted in four rural schools in Rakai district. All four schools (A, B, C and D) were located in the same sub-county. Schools Gov-A and Gov-B were government schools, whereas schools Priv-C and Priv-D were privately owned. Learner numbers in schools Gov-A and Gov-B were smaller than those in schools Priv-C and Priv-D. Data related to language repertoires of schools, classrooms and teachers were also collected, but from all 10 study schools: Kampala schools Priv-U (private) and Gov-W (government-owned), and Oyam schools Gov-N1, Gov-N2, Gov-N3 and Gov-N4 (all government-owned). This data on the language repertoires were collected with an aim of gaining an impression of the nature of multilingualism in both rural and urban schools. This was done bearing in mind that the current language policy mandates schools to select a dominant local language (i) as LoLT and subject in the case of rural schools and (ii) as subject only in the case of urban schools.

\section{FINDINGS}

In the next five sections, we present and discuss our findings. In the first three sections, we show that the different language policy documents do not use the same language in giving guidelines for the implementation of the MT education, that the policy has escape clauses and that the unclear stipulations are prone to different interpretations among schools, something that one might infer as equalling political play. In the last two sections, in turn, we refer to the interactions we had with teachers to demonstrate the frustrations experienced by teachers in implementing the MT education policy.

\section{Possible involvement of hidden agendas in the definition of mother tongue education in Uganda's policy documents}

As will be revealed in the ensuing discussion, the term 'mother tongue' has not consistently been used in Uganda's policy documents. This, we argue, may contribute to the confusion of employing MT in education and/or be a part of hidden agendas as concerns the implementation of MT education in Uganda. In the following paragraphs, we discuss what MT as a LoLT is in the Ugandan policy documents.

The Kajubi report (1989: 33) uses the terms 'area language' and 'language of wider communication' to refer to the proposed LoLT in P1 to P4. The languages singled out as area languages or languages of wider communication are Luganda, Lwo, Runyakitara/RunyoroRutoro and Runyankore-Rukiga, Ateso/Akaramojonj, and Lugbara. The Government White Paper (Government of Uganda, 1992: 18-19), which is an official government document on language policy in education, amended this to 'relevant local languages' and singled out Luo, Runyakitara, Luganda, Ateso/Akarimonjong, and Lugbara as LoLTs. National Curriculum Development Centre documents interchangeably use 'mother tongue', 'the first or familiar language' and 'area language' to refer to the MT that should be used as LoLT. The Ministry of Education and Sports' Education Sector Strategic Plan (2004, 2008) refers to MT as 'local language' or 'mother tongue' interchangeably. 
There now appears to be a shift from 'languages of wider communication' or 'dominant languages' to 'first languages' (L1s) as LoLT. For instance, Kateeba (2009: 3) states that:

[O]n the advent of thematic curriculum [sic], the number of languages approved by government as stated in the [Government White Paper] have been extended from 6 to 9. Besides the 9 languages that had orthography and written literature, 26 more languages have developed their orthographies and other necessary requirements and submitted to [National Curriculum Development Centre] for approval.

Furthermore, the National Curriculum Development Centre has set criteria to be met for a language to qualify as LoLT (cf. Rosendal, 2010), which suggests that any language in Uganda (no longer only so-called languages of wider communication) is now a potential LoLT. This lack of a consistent vocabulary to correctly define what 'MT' refers to in the Ugandan education system is potentially confusing to teachers and the public at large.

The mandate to choose a LoLT is given to the District Language Boards in conjunction with schools. A District Language Board is a group of individuals (mostly volunteers) charged with the responsibility of planning and overseeing the teaching, learning and use of a local language or language of wider communication as LoLT in primary schools in their district. District Language Boards are also charged with developing orthographies and instructional materials for a particular language. In practice, many districts in Uganda do not have operating District Language Boards (cf. Read \& Enyutu, 2004 for an early reference to this situation) and the formation of districts in Uganda seems to be an ongoing process. By end of September 2015, the number of districts stood at 132. The continuous creation of districts might well distract from the implementation of the language policy, because a particular school might be in one area with a particular dominant language, but upon such area being divided into two or more districts, the school might fall in a district with a different dominant language altogether.

A question to consider here is why an unclear policy was put in place. The fact that it is not clear whether every language in Uganda qualifies as a LoLT or whether only 'dominant languages' in schools should be used as LoLT causes one to wonder whether the current policy is somehow politically motivated. Almost a decade after the current language-in-education policy started to be implemented, confusion among schools and the general public is still present, and there is little evidence of an improvement in the quality of the education Ugandan children receive.

\section{What is mother tongue education? Policy documents versus experts' take}

A close reading of language-in-education documents in Uganda calls for some reflections. The first is whether MT education entails transmission of knowledge and skills from educator to learner using (i) the teacher's MT; (ii) the learner's MT; (iii) the dominant MT used in the locality where the school is located; or (iv) the dominant MT used in the region where the learner ordinarily lives. In Uganda, teachers are not deployed according to where their linguistic repertoire would be most beneficial to their learners. For this reason, it is not uncommon to find P1 to P3 teachers (in classes that are supposed to be instructed through MT) who cannot speak their learners' MT (cf. Benson, 2004; Woldemariam, 2007 regarding the challenges of failing to plan for teacher training and deployment countrywide). In sum, failure to plan for teacher deployment (and the same could be said of appropriate teacher training) is 
planning to fail in the implementation of the language-in-education policy, because teaching in the learners' MT will not be possible in all instances.

Teachers in this study reported that often the very teachers who had received training on how to employ MT education and how to handle the transitional class were transferred to other schools. Note that not all teachers at any given school received this training before MT education and thematic curriculum teaching were rolled out (cf. Altinyelken, 2010). Uncoordinated teacher transfers affect MT teaching in schools in that, when a trained teacher is transferred from a school, such a teacher will not necessarily be replaced with another trained teacher. The implication of this practice is that a school that loses a trained teacher due to transfer may well stop MT teaching.

In the literature on MT and bilingual or multilingual education, MT is generally defined as a language that one knows best or learnt to speak first. In many other contexts, MT is referred to as 'first language' (L1) (cf. Ball, 2011; Ouane \& Glanz, 2010; UNESCO, 2003). MT education refers to 'a system of multilingual education which begins with or is based on the learners' first language or mother tongue' (Kosonen \& Young, 2009: 13; World Bank, 2010: 10). Alidou et al. (2006: 4) define MT education as 'a language best known to the child', and Ball (2010: 7, 2011: 12) defines MT-based instruction as 'the use of the L1 as the primary language of instruction across the curriculum and throughout the school day'. The question arises as to whether MT education signifies transmission of knowledge in all disciplines - mathematics, social studies, cultural education, science, etc. - using the learner's language, or if MT education means that a local language, say Luganda or Acholi, is taught as a subject alongside English and other subjects, as is the case in the rural private schools in this study (schools PrivC and Priv-D) (also cf. Altinyelken, Moorcroft, \& van der Draai 2013). It appears as though MTs in Uganda have only been listed as LoLT but the social and cognitive justice that should result from MT education has not been brought to the attention of teachers. An appropriate question to ask here would be whether the language policies indeed only have a political agenda (Shohamy, 2006) and hoodwink the citizens, as Acemah (2014) has observed.

\section{Mother tongue teaching in urban schools}

Policy guidelines provide for teaching of MTs as subjects in urban schools. However, no guidelines are given on how to select which language should be taught as subject in any particular urban school. Teachers' responses in this study indicated a misinterpretation of the policy (cf. Johnson, 2009 for intepretation of language policy). For instance, respondent PrivU2 stated on a questionnaire that Ministry of Education and Sports guidelines did not allow MT teaching in urban schools; however, the policy documents clearly state that urban schools should teach a dominant area language as subject throughout the primary school years (cf. Government of Uganda, 1992; Kateeba, 2009; Ministry of Education and Sports, 2004). Furthermore, Respondent Priv-W4 claimed that urban schools were too multilingual to identify one dominant local language to be used as LoLT in these schools. This teacher's view is, however, unfounded, as from the language repertoires of teachers, classrooms and schools compiled during the course of this study, it transpired that the two urban schools (schools PrivU and Priv-W) each had a clear dominant local language; in both cases this was Luganda from P1 through P4 (and indeed these data were provided by the teachers themselves, indicating that they were aware that their individual classrooms had a dominant MT and were sure of what said language was). Moreover, Benson (2005) and Lucas and Katz (1994) are of the opinion that MT education is possible even in complex multilingual environments. 
Compared with Benson's (2005) observation, Ndoleriire (2004) has also observed that Kampala has Luganda as the dominant local language. Given that urban schools are required to teach MT as subject, the question arises as to how urban schools are expected to choose a local language to be taught as subject if they are 'too multilingual' to choose one to be used as LoLT. The confusion that the current language-in-education policy creates around choosing a language to be taught as subject and/or to be used as LoLT is symptomatic of politicking in language education, making the language-in-education policy but a document without proper guidelines for implementation.

\section{Commercialisation of teaching and learning materials used in mother tongue education}

One of the many challenges facing MT education in Africa is inadequate teaching and learning materials (see, among others, Bamgbose, 2004; Dutcher, 2003, 2004a, 2004b; Glanz, 2013; Read \& Enyutu, 2005; Stroud, 2001, 2002; Tembe, 2006). In Uganda's context, Nabirye and De Schryver (2010) and Trudell et al. (2012) have reported that materials for teaching and learning MTs are very scarce for all the years of primary schooling. This has resulted in, for example, teachers using an advanced user dictionary to teach P1 to P3 learners the MT in the absence of more appropriate materials (Nabirye \& De Schryver, 2010). The teachers in this study reported that the materials provided by the government were insufficient and of poor quality, as they did not fully address the curriculum; the materials did not arrive on time; and teachers were supplied with different materials from those which they requisitioned. Although this study observed a general consensus among teachers concerning the scarcity of teaching and learning materials in both rural government and rural private schools, the situation is deemed to be worse in government schools: government schools receive all their school materials from government, whereas private schools acquire theirs privately, and government school teachers reported that, for some subjects, curriculum materials were last received before 2006/2007.

The data gathered in this study suggest that there are particular publishing companies ${ }^{5}$ in which the government and/or Ministry of Education and Sports seem to have a particular interest. Teachers in this study indicated that, although they make well-researched and informed recommendations to the Ministry of Education and Sports for particular material to be purchased from a particular publishing company (because such material is better than that from other companies), the Ministry will insist that the teachers requisition the teaching material from a different company. From our interviews with teachers, it appeared that they wondered whether this was due to officials having a vested interest in particular companies or even due to outright corruption. Even if not one of these two is the case, teachers' narratives still demonstrated that procuring MT teaching and learning materials is politicised as it is influenced by Ministry of Education and Sports officials. Teachers viewed this disregard for their justified preferences as concerns learning materials as 'a game' which, we argue in this paper, appears to be politically motivated. This has far-reaching effects on not only MT education but the entire education system. The teachers pointed out that the materials from the publishing companies 'selected' by the Ministry of Education and Sports were substandard, yet they were the only materials available to government school teachers; therefore, teachers had no choice but to use these materials, resulting in learners not receiving all the content they are supposed to. For instance, one P3 teacher in school Gov-A said that the materials with which they taught a particular language did not cover certain aspects of grammar and that private schools had better quality teaching materials because the private schools could source their materials from the open market. Because all the materials government schools use are supplied by the 
government, government school teachers cannot easily access the better quality materials used by their colleagues in private schools. Other interviewed government school teachers pointed out that they were aware of good publishing companies in Uganda, but when they requested materials published by such companies from the Ministry of Education and Sports, they received other, cheaper (in the opinion of the interviewed teachers) materials from other companies. The teachers reported wondering whether the process of procuring teaching and learning materials in government schools involved institutionalised influence peddling, a practice that totals to politics in education.

Note also that respondents reported that the thematic curriculum materials were in English, yet rural teachers are required to teach in local languages. On the questionnaire, respondents expressed their inability to translate these materials into local languages and mentioned this as a reason why teaching in the MT was challenging. Consider the following selection of responses: ${ }^{6}$

Respondent A2: (i) We find a difficult of translating some words from English to MT.

(ii) We find a difficult in spelling some words.

(iii) All curriculums were written in English yet we are to teach in MT.

Respondent B7: I was not trained in writing [the local language]. So I find a problem in writing local language.

These responses demonstrate that teachers face the challenge of accessing the curriculum in local languages. Given the fact that not all teachers have the sufficient translation skills (cf. Respondent A2 above), and that they have not been trained in their MTs (cf. Respondent B7), different teachers are bound to translate the materials differently, potentially resulting in different subject matter being taught to learners across the country.

In only one of the 36 classroom observations conducted in this study (a P5 English class in Gov-B) did a teacher bring some textbooks into the class for the learners to use (although not enough for each learner to have one). Apart from complaints about quantity of the textbooks, there were also complaints about the quality of the teaching and learning materials. For example, one of the teacher resource books (National Curriculum Development Centre, 2006d) contained a number of orthographical errors as well as misleading information on Luganda orthography and grammar. The question arises as to the qualifications of the authors and their level of consultation with language specialists while compiling the material. The government school teachers narrated that English language textbooks were also mostly of poor quality, that the textbook content did not match the current syllabus and that learners were therefore not well exposed to all aspects of English that they were required to learn in their first three years of school. Generally, the teachers also said that even textbooks for subjects other than English were published in English, even for P1 to P3 where the LoLT is MT. Consider extracts 1 and 2 in this regard, which are representative of the types of responses teachers gave during the follow-up interviews after questionnaire completion. In the extracts, teacher turns are marked with $\mathrm{T}$ and the researcher's turns (those of the first author) with MS. Luganda text is in bold while the English translation is italicised.

Extract 1: Taken from group interview with teachers of school Gov-A

1T1: Gavumenti egenda n'erimitinga ssente zaayo, n'erowooza nti nno ekintu ky'ereese kirungi ate n'etandika okugamba ssente, kati ne kifuuka ekizibu. 
The government limits it expenditures thinking that what they have introduced is good, but then they begin to limit money and this makes it difficult.

${ }_{2} \mathrm{MS}$ : Mhm.

Yes.

3T3: Ne batatuwa na bitabo oba ffe ne balowooza nti tunaabiggya wa?

They even don't give us books. I wonder from where they expect us to get them.

${ }_{4} \mathrm{~T} 1$ : Kuba kati tolaba singa syllabuses zonna baazifulumya from P1 up to P7, naye from P5, five six seven, tezirina butabo buli ku syllabus.

Look, it would have been helpful if all syllabuses were published from P1 up to P7, but unfortunately P5, 6, 7 do not have books related to the current syllabus.

5T2: Kyakubiri.

Secondly.

${ }_{6} \mathrm{MS}$ : Ekyo sikiwulidde bulungi!

I didn't hear that.

7T1: Kati syllabus, baakyusaamu syllabus, enkadde eri...

The old syllabus was revised. The old syallabus is...

${ }_{8} \mathrm{MS}$ : Mhm, mhm.

Yes, yes.

9T1: Okulaba nga bagikyusizza okulaba nga waliwo amagundi ge baggyamu ne baleeta empya ze tulina okugoberera. Kati mu kuzigoberera, kitegeeza bw'ofulumya syllabus n'ebitabo bibeera mu press. Texts zirina okubeera nga weeziri, kati texts teziriiwo, syllabus efulumye mwaka mulamba ate texts tezifuluma.

The syllabus was modified to see to it that some learning areas were taken out and new syllabi were published, which we are supposed to follow now. When you publish a new syllabus, it means that at that time books are in press. Textbooks must be in place, but unfortunately they are not there. The syllabus was published; it is now a year, but the textbooks are not coming out.

${ }_{10}$ MS: Mhm. Eeeh!

I see.

11T1: Okiraba? Kati ffe baatutendeka transition mu 2010 ate gundi syllabus n'efululma, gwali mwezi oba Gwakusatu, ate syllabus n'efuluma mu Gwamunaana. Syllabus bw'efuluma mu Gwomunaana, 2011 ne balyoka baleetayo ku butabo.

Do you see that? For us, we were trained on how to handle the transitional class in March 2010 but the syllabus came out I think in August. When the syllabus was published in August 2011, it is at that time that some texts were brought to us.

${ }_{12} \mathrm{MS}$ : Nga wayiseewo mwaka mulamba.

When a whole year is gone.

13T1: Yee.

Yes.

${ }_{14} \mathrm{MS}$ : Ate nga mubadde mukola?

And yet you have been teaching/working?

15T1: Ate bakugamba genda okole.

Yes, they tell us to go and work/teach.

16T2: Kati P5 egoberera thematic class, P5, P6, P7, naye ate abo tebafunangako yadde n'ekitabo n'ekimu. Kati otuuka nga syllabus ekugamba kusomesa lesson eyo n'ogenda mu old text nga temuli lesson n'emu. 
P5 is following the thematic classes, P5, P6, P7, but these classes have never received any textbook. When the time comes that the syllabus demands that you teach such a lesson, you go to consult the old textbook, but you do not find any relevant lesson content.

Extract 2: Taken from group interview with government school A teachers

1T2: P1, P2, P3 babaweereza textbooks za Luzungu, kyokka ate nga bakwagala osomese mu lulimi lwo lwonna. Mu lulimi lwo lwonna.

$P 1, P 2, P 3$ were given English textbooks and yet you are expected to teach in your mother tongue. In any mother tongue that applies to you.

2T1: Mu Luganda.

In Luganda.

3T3: Naddala mu Luganda. Abalala tugamba nti bitulemeredde.

Most especially in Luganda. Some of us are saying that we have failed to do this.

${ }_{4} \mathrm{MS}$ : Temusobola kubivvuunula?

Are you not able to translate those materials?

5T3: Ffe situli Bazungu.

We are not English.

${ }_{6} \mathrm{MS}$ : Ate Omuzungu ye yandikaluubiriddwa kati ggwe oba oyanguyirwa anti Omuganda!

It is the English who would find it difficult, but you the Muganda [speakers of Luganda - MES] find it easier!

7T1: Aha, problem eriwo...

The problem at hand...

8T3: Anti nange waliwo ebigambo by'Oluzungu bye ssimanyi.

But there are some English words which I do not know.

${ }_{9} \mathrm{MS}:$ Mhm.

I see.

10T1: Voca, waliwo ekibakaluubirira!

Voca, ${ }^{7}$ there are some words which are difficult.

11T3: N'eby'Oluganda gye biri nga nkyogera naye empandiika n'ennema.

There are Luganda words which I can say but cannot write them out.

In turn 1 of Extract 1, teacher T2 mentioned that the Ministry of Education and Sports sent English textbooks to schools and yet they were supposed to teach the content of these textbooks in the MTs. In turn 3, teacher T3 said that some teachers had failed to implement what was expected of them, viz. to teach the curriculum in MT. When asked whether they could not translate the materials into Luganda (turn 5, extract 2), T3 answered somewhat sarcastically, 'We are not English'. This was a strong statement from the respondent, by which she implied that if she were expected to teach in Luganda, she should be given materials in Luganda and not in English. The teachers explained that there were English words they did not know, which would hinder their attempts to translate the curriculum materials into MT. In addition, T3 added that there were Luganda words that they could not write even though they could pronounce them (turn 10). If the reality is that teachers are not able to translate from English into MT when teaching, the question arises as to why teachers did not receive MT material to teach the MT curriculum. One possible reason why teachers' guides were written in English could be a desire by government to emphasise this language, i.e., a reason pertaining to linguistic ideology (cf. Stroud, 2002; Tollefson, 1991). As there is no shortage of professional English-Luganda 
translators, the reason cannot be a logistic one, unless there is limited funding for such translations.

It is clear from the above teachers' vignettes that the provision of materials in English differs from those in MTs. Also, practically, learners in government schools are not exposed to the same content as those in private schools given the fact that they do not use the same learning materials. Also note that, because the English materials available to teachers in government schools do not have the required content for particular levels of learning, learners in government schools would not be exposed to the same content for English language learning. In sum, the education system in Uganda would be producing two sets of learners, brought about by the discretionary provision of teaching and learning materials and the failure of government to enable the implementation of the language-in-education policy.

\title{
The politics of tests and examinations in mother tongue education
}

Shohamy (2006: xvi) contends that:

[T] he study of LP [language policy] should not be limited to formal, declared and official policies but rather to the study of the powerful mechanisms that are used in most societies nowadays to create and perpetuate 'de facto' language policies and practices.

Shohamy believes that 'real policies' of language are created through language-in-education policies, language tests and language in the public space (cf. Cleghorn, Merritt \& Abagi, 1989; Ndlovu, 2013). Kaplan and Baldauf (1997) argue that, in multilingual contexts, tests in a particular language signal whether that language is important or not, and may also determine the acceptance of a language and rejection of others. The testing or non-testing of a language manipulates language policy and creates a de facto policy which, in a way, represents the language policy realities in a community and/or country (cf. Makoni, 2011; Nyika, 2008;

Shohamy, 2006). Tests are therefore an incentive to learn a language: if a language is for instance not examined at the end of an educational level, it will most likely receive minimal attention in the teaching process.

Furthermore, the current language-in-education policy of Uganda has an escape clause for the examination of MTs in Uganda (Government of Uganda, 1992: 19):

\begin{abstract}
However, students may or may not offer this subject for PLE [end of primary school] examination. UNEB [Ugandan National Examination Board] will, nevertheless, provide for examination in all the five main Ugandan languages (Luo, Runyakitara, Luganda, Ateso/Akarimonjong and Lugbara) in PLE for those who study any of those languages as subject for examination.
\end{abstract}

As Uganda's education system appears to be examination oriented, the non-examined subjects, like MTs, are generally not given as much attention as the examined subjects are, despite what school timetables may indicate (cf. Ssentanda, 2013). For example, refer to following extract which we reproduce from Ssentanda (2013: 286):

1MS: Kati mu P4 ne mu P5 Oluganda musigala mukyalusomesa? Do you then continue teaching Luganda in P4 and P5?

1T1: Yee, kyandibadde nti wonna ppaka kumalako seven... 
Yes, it would be the case that it is taught all the way to $[\mathrm{P}]$ seven...

3T2: Nga subject.

As a subject.

4T1: Nga subject, naye lwakuba nti olumu munnange nga bw'omanyi n'abantu obudde...

As a subject, but my friend, as you know some people with time...

5T2: Ate nga n'engeri gy'etali examinable ... And also being an unexaminable subject...

6T1: Kati ekyo kiwa abantu obunafu. With that people become lazy.

${ }_{7} \mathrm{MS}$ : Eeh.

I see.

8T1: Ne banafuwa. Abantu awo bajjamu obunafu n'agamba eeh... They become lazy; at that point people become lazy saying...

${ }_{9} \mathrm{MS}$ : N'agamba nti lwaki obudde tubumalira wano ng'ate science ye wookubuuzibwa?

They ask a question, 'Why do we waste time with this yet it is science that will be examined?'

10T1: Ahaa. Kuba ky'ova olaba nti bw'ogenda mu gundi, twesiba ku major. Zino eziri major ze tukola ki?

Yes. That's why you find that when you go to this..., we only concentrate on majors. The major ones are what we do, right?

The teacher attitude that a certain subject is not as important as some others can eventually trickle down to learners and their parents. One of the reasons why parents move their children from government to private schools (Ssentanda, 2013) (at least to rural private schools), where teaching and learning is conducted in English, is because parents do not understand why there is an emphasis on MT teaching if the MT is not valued sufficiently as a subject to be examined at the end of primary school.

Teachers in this study also reported that they had a challenge when setting examinations. Ssentanda (2013) explains that private schools use English as LoLT in P1 to P3 while government schools use MT. This also means that the two sets of learners in the two sets of schools would not sit the same set of examinations. However, because government school teachers want to see their learners compete with those in private schools, they often try to give them examinations set for private schools. Unfortunately, teachers reported that government school learners fail such examinations. The reason for government school learners' failure of examinations meant for private school learners is largely language related. Recall that government school learners are taught and examined in MT from P1 up to P4 whereas those in private schools are taught and examined in English from pre-primary onwards (cf. Ssentanda, 2014). Even though learners in government schools may have covered the same subject content that learners in private schools have, they do so in their MT only; they are not exposed to the English terminology in the subjects they are learning. It should therefore not be surprising to see them failing examinations set in a language with which they are not as familiar as learners in private schools are (cf. Banda \& Kirunda, 2005).

Interestingly, none of the schools in the study area set their termly examinations themselves; they all bought examinations from private companies. These companies also provide two sets of examinations, some in local languages (for government schools) and others in English (for 
private schools). This state of affairs in the education system and particularly concerning the LoLT in lower primary appears to be unmonitored by government. It is therefore not surprising that in this study area, parents who can afford to pay schools fees move their children from government schools to private schools, as mentioned earlier. In sum, until MTs are made an examined subject at end of primary school level, the current language-in-education policy is likely to remain but a mere policy document in Uganda's education system.

\section{CONCLUDING REMARKS}

Findings presented in this paper point to political play involved in formulating language-ineducation policies in Uganda, policies which would, in principle, be promoting MT education. From the evidence given, it is clear that MT education in government schools compares poorly to the English education in private schools, and one can also say that MT education is not working, either in government schools or in private schools. This study's data demonstrate that MT education was poorly planned. Theoretically, learners in government schools, in which MT education is practised, should be outperforming those in private schools, who are instructed in English from the beginning of their schooling. However, as MT education is not well facilitated - teacher deployment and teacher transfer are not well planned, materials are not made available in the learners' MT, teachers are not trained to teach in the MT, etc. - the benefits of MT education are not experienced by learners in government schools. Therefore, these learners are disadvantaged for that matter. This paper has demonstrated that teachers in government schools are not provided with the materials they consider appropriate for the task of implementing MT education; the materials at their disposal are often incomprehensive and in English only. This could mean that the subject content delivered to learners in government schools is poorer than that delivered to private school learners. The task is also more difficult for government school teachers, particularly because they have to translate the materials themselves, a task they confess that they cannot do well. This means that much is lost between the printed textbook content and its delivery in class.

Obviously, the task ahead is to improve MT education in Uganda so that the children in government schools are on equal footing with those in private schools. It is anticipated that, if MT education is well planned and facilitated, the good MT education practices will trickle down to private schools, because although learners in private schools perform better than those in government schools, they do not do so without the difficulties that come with learning through an unfamiliar language. Of the many tasks that lie ahead to improve MT education in Uganda, teacher training is on the fore. It has been reported that, when teachers are not trained for a particular task, they usually resist it when it is later demanded of them to perform this task in practice. This means that if MT education is to succeed, training on the teaching of and through the medium of MT should take place prior to teachers' deployment in schools. Relatedly, as private schools are not under direct supervision of the government, teachers in these schools are more likely to resist policies and practices that do not match with their training. This is more reason for educating teachers about MT education and its benefits prior to their deployment.

Finally, the aim of this paper was not to fault English education in private schools but rather to show the weaknesses in the formulation of MT education policies which pave the way for English-only education as is the practice in private schools in Uganda today. Our aim also was not to call for the disregard of English education but to show that when MT education policies are poorly formulated and when their implementation is not facilitated as required, (i) learners 
miss out on the benefits that come with MT education and (ii) improvement in literacy skills, which was the original drive for the current Ugandan language-in-education policy, will remain unattainable.

\section{ACKNOWLEDGEMENTS}

The first author acknowledges the funding that was awarded to him by the Graduate School of Arts and Social Sciences to pursue his doctoral studies full-time at Stellenbosch University. In addition, he acknowledges the financial assistance of the Directorate of Graduate Training at Makerere University for completing the fieldwork done for the study reported on in this paper.

\section{END NOTES}

\footnotetext{
1 'Mother tongue' usually refers to a language that one knows best or learnt to speak first. In many contexts, mother tongue is referred to as 'first language' (L1; see UNESCO, 2003; Ouane \& Glanz, 2010; Ball, 2011). We acknowledge the terminological distinctions between 'mother tongue', 'first language' and 'home language', but the most frequently used term in the literature on mother tongue education (and in bilingual or multilingual education) is 'mother tongue' and as such this is the term we use in this paper.

${ }^{2}$ Note that Makerere University categorises these languages as one language and teaches them under the subject name Runyakitara (Bernsten, 1998).

${ }^{3} \mathrm{P} 3$ is the third year of formal education (excluding preschool years), equivalent to Grade 3 in the South African education system.

${ }^{4}$ There was however an apparent oversight in the strategy in that learners' MT was used as LoLT for the first years of school but were not compulsory examination subjects at the end of primary school. The nonexamination of MTs at the end of primary schooling has been pointed out by teachers as one factor that demotivates the teaching of MTs in Uganda even to this date (cf. Ssentanda, 2013). This matter is addressed later in this paper.

${ }^{5}$ Although respondents referred to such companies by name, these companies are, for ethical reasons, not named anywhere in this paper.

${ }^{6}$ Responses are presented verbatim, with spelling and grammar mistakes left uncorrected.

${ }^{7}$ Voca (short for vocabulary) is a word in Ugandan English used mostly by the youth to mean 'a word of which you do not know the meaning'.
}

\section{REFERENCES}

ACEMAH, H. 2014, March. Is thematic curriculum a panacea or a gimmick to hoodwink the wananchi? Daily Monitor. Available from http://www.monitor.co.ug/OpEd/Commentary/Is-thematic-curriculum-a-panacea-or-agimmick/-/689364/2226860/-/ow7qg2/-/index.html [Accessed 14 November 2016].

ALIDOU, H, A BOLY, B BROCK-UTNE, Y SATINA, Y DIALLO, K HEUGH \& HE WOLFF. 2006. Optimizing learning and education in Africa - the language factor: A stock-taking research on mother tongue and bilingual education in Sub-Saharan Africa education. Libreville, Gabon,: Association for the Development of Education in Africa (ADEA) UNESCO Institute for Education. Available from http://www.adeanet.org/adeaPortal/adea/downloadcenter/Ouga/B3_1_MTBLE_en.pdf [Accessed 23 March 2012].

ALTINYELKEN, HK. 2010. Curriculum change in Uganda: Teacher perspectives on the new thematic curriculum. International Journal of Educational Development, 30(2):151-161. doi:10.1016/j.ijedudev.2009.03.004

ALTINYELKEN, HK, S MOORCROFT \& H VAN DER DRAAI. 2013. The dilemmas and complexities of implementing language-in-education policies: Perspectives from urban 
and rural contexts in Uganda. International Journal of Educational Development. doi:10.1016/j.ijedudev.2013.11.001

BALL, J. 2010. Educational equity for children from diverse language backgrounds: Mother tongue-based bilingual or multilingual education in the early years. In Presentation to UNESCO International Symposium: Translation and Cultural Mediation. Paris: UNESCO. Available from http://dspace.library.uvic.ca:8080/bitstream/handle/1828/2457/UNESCO_Summary_20 10.pdf [Accessed 20 March 2013].

BALL, J. 2011. Enhancing learning of children from diverse language backgrounds: mother tongue-based bilingual or multilingual education in the early years. Analytical review commissioned by the Unesco Education Sector. France: United Nations Educational, Scientific and Cultural Organization. Available from http://unesdoc.unesco.org/images/0021/002122/212270e.pdf [Accessed 20 March 2013].

BAMGBOSE, A. 2004. Language of instruction policy and practice in Africa. Available from http://www.unesco.org/education/languages_2004/languageinstruction_africa.pdf [Accessed 20 March 2013].

BANDA, F \& R KIRUNDA. 2005. Factors affecting the initial literacy development of urban and and rural learners in the Iganga district, Uganda. Per Linguam, 21(2):1-23. doi: $10.5785 / 21-2-73$.

BENSON, C. 2004. Do we expect too much of bilingual teachers? Bilingual teaching in developing countries. International Journal of Bilingual Education and Bilingualism, 7(2\&3):204-220.

BERNSTEN, J. 1998. Runyakitara: Uganda's 'new' language. Journal of Multilingual and Multicultural Development, 19(2):93-107.

BOURDIEU, P. 1991. Language and symbolic power (JB Thompson, Ed.). Cambridge: Polity Press.

CLEGHORN, A, M Merritt \& JO Abagi. 1989. Language policy and Science instruction in Kenyan primary schools. Comparative Education Review, 33(1):21-39.

DUTCHER, N. 2003. Promise and perils of mother tongue education. Available from http://www.silinternational.net/asia/ldc/plenary_papers/nadine_dutcher.pdf [Accessed 5 April 2012].

DUTCHER, N. 2004a. Expanding educational opportunity in linguistically diverse societies (2nd ed.). Washington, DC: Centre for Applied Linguistics.

DUTCHER, N. 2004b. Language policy and education in multilingual societies: Lessons from three positive models. Linguapax Congress. Barcelona, Spain.

FERGUSON, G. 2013. The language of instruction issue: Reality, aspiration and the wider context. In McIlwraith, H (Ed.). Multilingual education in Africa: Lessons from the Juba Language-in-Education Conference. UK: British Council. 17-22.

GLANZ, C. 2013. Why and how to invest in African languages, multilingual and multicultural education in Africa. In McIlwraith, H (Ed.). Multilingual education in Africa: Lessons from the Juba Language-in-Education Conference. UK: British Council. 57-67.

GOVERNMENT Of UGANDA. 1992. Government white paper on the implementation of the recommendation of the report of Education Review Commission. Kampala: Uganda Government.

HEUGH, K, C BENSON, B BOGALE \& MAG YOHANNES. 2007. Final report study on medium of instruction in primary schools in Ethiopia. Available from http://mlenetwork.org/sites/default/files/Final_report_study_on_Medium_of_Instructio 
$\underline{\text { n_in_primary_schools_in_Ethiopia_-_Heugh_et_al_2007.pdf }}$ [Accessed 12 March 2013].

HOPSON, RK. 2011. Reconstructing ethnography and language policy in colonial Namibia schoolling: Historical perspectives on St Mary's school at Odibo. In McCarty, TL (Ed.). Ethnography and language policy. New York: Routledge. 99-118.

JOHNSON, DC. 2009. Ethnography of language policy. Language Policy, 8(2):139-159. doi:10.1007/s10993-009-9136-9

KAJUBI, WS. 1989. Education for national integration and development: Report of the Education Policy Review Commission. Kampala, Uganda: Ministry of Education.

KAPLAN, RB \& RB BALDAUF. 1997. Language planning: From practice to theory. Clevedon: Multilingual Matters.

KATEEBA, C. 2009. Thematic curriculum; implications for mother tongue education in Uganda. Mother Tongue Day Conference. Makerere University, Institute of Languages: National Curriculum Development Centre.

KIRKPATRICK, A. 2013. The lingua franca approach to the teaching of English: A possible pathway to genuine multilingualism in local languages and English. In McIlwraith, $\mathrm{H}$ (Ed.). Multilingual education in Africa: Lessons from the Juba Language-in-Education Conference. UK: British Council. 11-15.

KOSONEN, K \& C YOUNG. 2009. Introduction. In Kosonen, KK \& C Young (Eds.). Mother tongue as a bridge language of instruction: Policies and experiences in Southeast Asia. Bangkok, Thailand: Southeast Asian Ministers of Education Orgranisation (SEAMEO). 8-18.

LASEBIKAN, EL, R ISMAGILOVA \& R HUREL. 1964. Report of the study on the use of the mother tongue and the preparation of alphabets for literacy. Available from http://unesdoc.unesco.org/images/0014/001481/148113eb.pdf [Accessed 2 March 2013].

LUCAS, T \& A KATZ. 1994. Reframing the debate: The roles of native languages in Englishonly programs for language minority students. TESOL QUARTERLY, 28(3):537-561.

MAKONI, S. 2011. A critical analysis of the historical and contemporary status of minority languages in Zimbabwe. Current Issues in Language Planning, 12(4):437-455.

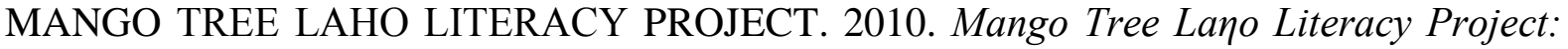
Early Grade Reading Assessment P1 Baseline Survey 2010. Kampala, Uganda.

MINISTRY OF EDUCATION AND SPORTS. 2004. Ministry of Education and Sports Education sector strategic plan 2004-2015 education. Kampala, Uganda: Ministry of Education and Sports.

MINISTRY OF EDUCATION AND SPORTS. 2008. Ministry of Education and Sports draft revised education sector strategic plan 2007-2015. Kampala, Uganda: Ministry of Education and Sports.

NATIONAL CURRICULUM DEVELOPMENT CENTRE. 2006a. Primary school curriculum primary 2. Kampala: National Curriculum Development Centre.

NATIONAL CURRICULUM DEVELOPMENT CENTRE. 2006b. Thema: The newsletter of the thematic curriculum. Kampala: National Curriculum Development Centre.

NATIONAL CURRICULUM DEVELOPMENT CENTRE. 2006c. The national primary school curriculum for Uganda, primary 1. Kampala: National Curriculum Development Centre.

NATIONAL CURRICULUM DEVELOPMENT CENTRE. 2006d. Teachers' Resource Book (Luganda). Kampala: National Curriculum Development Centre.

NATIONAL CURRICULUM DEVELOPMENT CENTRE. 2011. Thema: The newsletter of the thematic curriculum. Kampala: National Curriculum Development Centre. 
NDLOVU, E. 2013. Mother tongue education in official minority languages of Zimbabwe: A language management crtique. The University of the Free State. Available from http://etd.uovs.ac.za/ETD-db//theses/available/etd-07182013091525/unrestricted/NdlovuE.pdf [Accessed 18 September 2013].

NDOLERIIRE, OK. 2012. Some phonetic characteristics in English and French that facilitate or complicate pronunciation by Runyakitara speakers of English and French. Kampala, Uganda: Paper presented at the Linguistics Seminar, November 2, 2012.

NYIKA, N. 2008. 'Our languages are equally important': Struggles for the revitalisation of the minority languages in Zimbabwe. Southern African Linguistics and Applied Language Studies, 26(4):457-470.

OUANE, A \& C GLANZ. 2010. Why and how Africa should invest in African languages and multilingual education: An evidence- and practice-based policy advocacy brief. Hamburg, Germany: UNESCO Institute for Lifelong Learning. Available from http://unesdoc.unesco.org/images/0018/001886/188642e.pdf [Accessed 5 May 2012).

PIPER, B \& E MIKSICK. 2011. Mother tongue and reading: Using Early Grade Reading Assessments to investigate language-of-instruction policy in East Africa. In Gove, A \& A Wetterberg (Eds.). The Early Grade Reading Assessment: Applications and interventions to improve basic literacy. Research Triangle International. 139-182.

READ, T \& S ENYUTU. 2004. The Uganda primary curriculum review road map: For the implementation of the curriculum reforms recommended by the primary curriculum review report and approved by the Ministry of of Education and Sports.

RICENTO, T. 2006. Language policy: theory and practice - an introduction. In Ricento, T (Ed.). An introduction to language policy: theory and method. USA: Blackwell Publishing. 10-23.

SALDANA, J. 2009. The coding manual for qualitative researchers. London: SAGE. Available from http://www2.unine.ch/files/content/sites/mapschaire/files/shared/documents/supports_cours/Saldana_ch1.pdf [Accessed 19 March 2014].

SHOHAMY, E. 2006. Language policy: Hidden agendas and new approaches. New York: Routledge.

SSEKAMWA, JC. 2000. History and development of education in Uganda (2nd ed.). Kampala, Uganda: Fountain Publishers Ltd.

SSEKAMWA, JC. 2008. Development and challenges of formal education in Uganda. Entebe, Uganda: Nkumba University.

SSENTANDA, ME. 2013. Exploring connections: Reflections on mother-tongue education in postcolonial Uganda. Stellenbosch Papers in Linguistics Plus, 42:281-296.

SSENTANDA, ME. 2014. 'Have policy makers erred?' Implications of mother tongue education for pre-primary schooling in Uganda. Per Linguam, 30(33):53-68. doi:10.5785/30-3-547.

STROUD, C. 2001. African mother-tongue programmes and the politics of language: Linguistic citizenship versus linguistic human rights. Journal of Multilingual and Multicultural Development, 22(4):339-355.

STROUD, C. 2002. Towards a policy for bilingual education in developing countries. Stockholm: Swedish International Development Cooperation Agency.

TEMBE, J \& B NORTON. 2008. Promoting local languages in Ugandan primary schools: The community as stakeholder. The Canadian Modern Language Review, 65(1):33-60. doi:10.31838/cmlr.65.1.33

TOLLEFSON, JW. 1991. Planning language, planning inequality: Language policy in the community. London and New York: Longman Inc. 
TURNBULL, J. 2010. Oxford advanced learners' dictionary: International students' edition. (Hornby, J Turnbull, D Lea, D Parkinson, P Phillips, B Francis, ... M Ashby, Eds.). Oxford: Oxford University Press.

UGANDA NATIONAL EXAMINATIONS BOARD. 2010. The achievement of primary school pupils in Uganda in numeracy, literacy in English and local languages: National Assessment of Progress in Education. Uganda National Examinations Board, Uganda, Uganda: Uganda National Examinations Board.

UNESCO. 1997. Intergovernmental conference on Language policies in in Africa. Harare, Zimbabwe.

UNESCO. 2003. Education in a multilingual world: Unesco education position paper. Paris, France: United Nations Educational, Scientific and Cultural Organization.

UNESCO Regional Office for Education in Africa. 1985. African community languages and their use in literacy and education. Dakar.

UWEZO. 2011. Are our children learning? Annual learning assessment report 2011. Uganda, Kampala: Uwezo.

UWEZO. 2012. Are our children learning? Literacy and numeracy across East Africa. Nairobi, Kenya.

WOLDEMARIAM, H. 2007. The challenges of mother-tongue education in Ethiopia: The case of North Omo area. Language Matters, 38(2):210-235.

WORLD BANK. 2010. Mother tongue instruction and learning for quality education: The World Bank's education sector strategy 2020.

\section{BIOGRAPHICAL NOTES}

Dr Medadi E Ssentanda is a lecturer in the Department of African Languages, Makerere University and Research Associate, Stellenbosch University. He is a reader in the field of language education, particularly early literacy development in multilingual environments, language and the curriculum and teachers' attitudes. He was part of the 2012-2014 cohort scholarship holders of Graduate School of the Arts Faculty at Stellenbosch University. He was also appointed a research associate in the Department of General Linguistics, Stellenbosch University for the period 2015-2018. Email: medadies@gmail.com or ssentanda@chuss.mak.ac.ug

Kate Huddlestone is a lecturer in the Department of General Linguistics at Stellenbosch University. Her research interests include the grammar of Afrikaans, specifically negation in Afrikaans, code switching, especially in educational contexts, and sign language linguistics. Email: katevg@sun.ac.za.

Frenette Southwood practiced as a speech-language therapist before joining the Department of General Linguistics at Stellenbosch University as lecturer and researcher in 2000. Her research focuses on child language development and disorder in multilingual contexts. Email: $\underline{\text { fs@sun.ac.za }}$ 